\title{
THE EFFECTIVENESS OF HUMAN CAPITAL IN THE CONTEXT OF THE DIGITAL TRANSFORMATION OF THE ECONOMY: THE CASE OF UKRAINE
}

\author{
Volodymyr Rodchenko \\ V. N. Karazin Kharkiv National University, Ukraine \\ Ganna Rekun \\ V. N. Karazin Kharkiv National University, Ukraine \\ Larysa Fedoryshyna \\ University of Economics and Entrepreneurship, Ukraine
}

Ihor Roshchin

University of Customs and Finance, Ukraine

Svitlana Gazarian

The National Academy of Public Administration under the President of Ukraine

\begin{abstract}
The purpose of this article is to empirically assess the qualitative parameters of the effectiveness of human capital for business digitalization in Ukraine. Using a survey of 500 business representatives in Ukraine and the Fibonacci rule, and taking into account the digital business transformation level, the qualitative levels of human capital efficiency have been classified. Also, using the method of principal components, the system of factors of human capital's effectiveness for the intensification of digitalization has been empirically substantiated. An empirical model for assessing the quantitative levels of human capital effectiveness in the context of digital business transformation has been developed using integral assessment. The potential for the development of business digitalization based on the factors' actual values has been determined. The results obtained can become the basis to improve the quality of human capital for the successful introduction of modern digital technologies into the country's business processes.
\end{abstract}

Keywords: Ukraine, human capital, digital economy, business, digital transformation, efficiency.

DOI: http://dx.doi.org/10.15549/jeecar.v8i2.686

\section{INTRODUCTION}

In comparison to traditional forms of management, the digital economy modifies the structure of economic relations, stimulates the intensive growth of intra-industry competition, expands the scale of market relations, and 
enhances the competitiveness of individual industries and individual countries on the scale of the global market. Although the volume of the world economy decreased by $4.4 \%$ in 2020 due to the spread of the COVID 19 pandemic (Congressional Research Service, 2021), the pandemic also provoked an acceleration of the digitalization of economic relations in the world, the leaders of which were countries such as South Korea, Singapore, Hong Kong, Estonia, Taiwan and the UAE (The Fletcher School, 2021). The transition to the digital economy changes the labor market and the requirements for human resources significantly. The active development and spread of information technologies in society have led to the formation of a new social and labor structure characterized by innovative forms of employment. There is a transformation of the country's social structure, as the rapid technological progress creates new requirements for all players in the labor market, changes hiring practices, increases flexibility and mobility, and increases the level of education requirements (Ragnedda, 2018). According to experts and business representatives, because of the latest trends in the world by the end of 2022 digitalization will provoke a reduction in the number of employees who are employed full-time (Walwei, 2016).

Ukraine belongs to the category of promising countries for the digitalization of business, like all post-socialist camp countries, according to the global ranking of the Digital Intelligence Index (The Fletcher School, 2021). This zone is characterized by economies in which the digital infrastructure is still limited but is being rapidly digitalized. In terms of the level of development of digitalization, Ukraine is significantly inferior to world leaders. According to the Networked Readiness Index ranking (the World Economic Forum index, which is calculated based on many indicators - from public procurement to the impact of digitalization on society), Ukraine ranks 64th out of 139 countries in 2020. Countries with a high-income level usually occupy the leading positions in the economy's ranking of informatization (Portulans Institute, 2021). Many companies today are trying to introduce the technologies of industry 4.0. into business in Ukraine, yet few manage to do this on a scale to allow them to achieve a significant financial and economic effect (Yanovska et al., 2019). The main destructive factors are not only the insufficient level and quality of mobile internet access and the weakness of the institutional environment, but also, above all, the low level of efficiency of human resources. Labor productivity is an important economic indicator of human capital quality, which largely determines economic growth and business digitalization (Ballestar et al., 2020). Today, human capital in Ukraine is characterized by a deficient level of productivity; at the beginning of 2020, labor productivity was $\$ 20,496$, while the average for a sample of 189 countries was $\$ 42,751$ in output per worker (International Labor Organization, 2021 ), which put it $115^{\text {th }}$ out of 189 . This level of productivity is the lowest in Europe, and of the countries of the post-socialist camp, only Uzbekistan $(\$ 14,883)$, Tajikistan $(\$ 13,345)$, and Kyrgyzstan $(\$ 9,293)$ have lower levels of labor productivity than Ukraine (International Labor Organization, 2021). The low level of labor productivity predetermined the persistence of a stable trend towards low investment activity. For example, over the past 10 years, only about $15 \%$ of industrial enterprises in Ukraine have implemented innovative processes and products in production activities (State Statistics Service of Ukraine, 2021). And the transition to digitalization does not stimulate production returns, which leads to a weak digitalization of the national economy. This, in turn, carries the risk of increased differentiation in the incomes of the population within the country and the technological backwardness of Ukraine on the world stage.

Ukraine is only at the beginning of its path to informatization of the economy, and the threat of a low level of productivity of human resources is not the emergence of a whole class of "superfluous" people, total retraining, and destruction of the traditional foundations of worthy social guarantees in the future, and so on. The threat is the inconsistency of human capital quality in the country with modern trends in economic development (Yanovska et al., 2019). Thus, the period of the emergence of the digital economy and digitalization of business requires a quick response to changes in the labor market, investments in human capital 
and new ways to improve it qualitatively, adapt to new conditions, and program measures from the state. Therefore, this scientific study was aimed at an empirical assessment of human capital parameters at the present stage of the digitalization of business in Ukraine and the search for and determination of the key factors of its effectiveness.

\section{LITERATURE REVIEW}

In the scientific literature, digitalization of economic activity is understood by most scientists as a new structural change in the technological structure of the economy, in which digital data, processing large volumes of it and the use of analysis results are the key factors of production (Ragnedda, 2018). Many scientific studies in the field of human capital were based on using a variety of empirical and analytical tools and confirmed the close relationship between digitalization, innovation, and the productivity of human capital (Voronin et al., 2020; Hu, 2021; Jeske, Würfels \& Lennings, 2021) The effective development of human capital and the possibility of productive use to ensure sustainable development of economic ties and the establishment of stable ties with business, science, and education in the context of informatization of economic activity is increasingly acquiring the status of a priority strategic direction for the development of the modern economy (Jeske, Würfels \& Lennings, 2021).

Many scientists adhere to the point of view of the positive effects of the impact of digitalization on the development of the national and global economy and business, justifying this by the fact that opportunities for the exchange of large amounts of data and their accumulations are opening up (Jeske, Würfels \& Lennings, 2021; Mahmood \& Mubarik, 2020). This allows for the process of collecting information, forming a common information space, making reliable predictions, making informed decisions, extracting all kinds of benefits, replacing human routine work with machines, and the like (Jeske, Würfels \& Lennings, 2021). But on the other hand, scientists also noted the digitalization of the economy, the emergence of risks of data loss, business loss, job loss, security breaches, and the need for modernization (Walwei, 2016; Chen, 2020). This also explained the negative impact of technology diffusion on income differentiation (Tewathia, Kamath \& Ilavarasan, 2020). Skill-biased technological change is a significant driver contributing to the strengthening of this inequality within a particular country and across countries (Law et al., 2020).

As evidenced by the results of leading studies, the digitalization of the economy is an inevitable stage of evolution, and this direction is relevant for all countries of the world (Ragnedda, 2018). Therefore, potential threats to digitalization need to be addressed, and rather quickly, since the delay is also fraught with risks. Digitalization of the economy, or in a particular business, is a chance for both developed economies and developing ones. As a result of the efficiency and thoughtfulness of digitalization, significant changes can occur in geopolitical and geo-economic leadership (Horoshko et al., 2021). Still, there is also a risk of technological lag, which can inevitably damage the country's national interests and security (Law et al., 2020).

Business informatization, like any developing system as a source of movement, is characterized by certain contradictory aspects of human capital development as one of the key factors in the development of information technology and the transformation of production into a post-industrial one. With the accumulation of significant intellectual wealth and the development of modern technologies, achievements in labor productivity are minimal (Yanovska et al., 2019). There are various reasons for this contradiction: the imperfection of approaches to statistical collection and processing of data on labor productivity in the digital economy (Ballestar et al., 2020); the presence of a time interval for obtaining the final result and the introduction of innovations (Hu, 2021; Megits, Neskorodieva \& Schuster, 2020); and informatization affects labor productivity only in certain high-tech industries (Jeske, Würfels \& Lennings, 2021). It seems that the effectiveness of the information economy cannot be assessed by the traditional characteristics of labor productivity as a qualitative parameter of human capital. We 
agree with this point of view. Labor productivity is a measure of the quantity of labor of a specified quality (Ballestar et al., 2020). The main sign of labor productivity is necessarily creating a material product in the production activities of people (Yasmin, El Refae \& Eletter, 2019). The digitalization of economic activity presupposes the priority development of the service sector; therefore, it is advisable to use labor efficiency as an indicator of the quality of human capital within the information economy as a broader concept covering all areas of labor activity, including both production and nonproduction (Jeske, Würfels \& Lennings, 2021). A sign of or a significant difference between labor productivity and labor efficiency is the ratio of ergotic and scientific and technical factors. Simultaneously, in increasing labor efficiency, the ergot or human factor acts as a more significant factor, which is the driving force behind the informatization of the economy.

The problems of employment of the population in the digital economy take on a new meaning. Human capital is viewed as the key source of wealth, which requires a conceptual shift in people's consciousness from the position of "maximizing profit" to the position of "maximizing utility" (Hu, 2021). The digital economy requires completely new skills and competencies. To leverage digital technology and scale-up businesses nationally and internationally, organizations need people with the right mix of technical, business, interpersonal and creative skills (Mahmood \& Mubarik, 2020). The inconsistency of the skills of applicants with the requirements set by employers within globalization processes and the digitalization of all aspects of economic activity, as experts have noted, is usually caused by either the failure of the education system or the sequence of changes in the modern labor market (Law et al., 2020). At the same time, studies by international experts showed that the presence of creative people who can think critically, correctly present their ideas, as well as a high level of education in general, do not always automatically lead a society to sustainable growth and prosperity (Faggian, Partridge \& Malecki, 2016). For the stable development of the informatization of the economy, the optimal use of existing skills and the development of existing skills' potential becomes a necessary condition, constantly paying attention to the productivity of human resources. Because of the controversial nature of the issue of the effectiveness of human capital in the context of the digitalization of the economy, our study identified qualitative parameters of the effectiveness of human capital which ensure the development of informatization of the economy in a developing market, taking into account the current state of human resources.

\section{METHODOLOGY}

To obtain quantitative data on human capital's effectiveness, compliance with business digitalization, and increasing business performance using digital technologies, a survey of 500 representing 90 medium-sized companies in Ukraine was administered. The study sample did not include IT companies since their use could distort the results towards an increase in human capital development, especially concerning digital competencies. The survey was conducted remotely during November 2020-February 2021 using Google Form by prior agreement with the respondents. Participation in the survey was voluntary. For statistical processing of the results, 426 questionnaires that were received and filled out were used.

The authors developed the questionnaire (see The human capital effectiveness in the context of the digital transformation of the economy, 2021), following the European Commission (2019), Mahmood \& Mubarik (2020), Yanovska et al. (2019) and Ballestar et al., (2020). It consisted of 3 blocks. Block 1, "Profile of respondents," included questions regarding the respondent's age, gender, status in the company, and the scope of the company. This block aimed to obtain characteristics of the respondents, which ensures the representativeness of the questionnaire and could influence the estimates. Block 2, "Personnel's perception of business digitalization", involved answering questions (choosing one answer option most suitable for the respondent) that relate to understanding the essence of business digitalization, its features, and impact on the company. For statistical processing of the results in the course of the 
analysis, the answer option "a" was assigned the value "0" points, "b" - "5" points, "c" - "10" points. Block 3 assumed assessment on a 5point scale of statements that relate to the development of personal characteristics and professional competencies of personnel necessary for the development of digital technologies in business and increasing its efficiency using these technologies. The minimum score, "0", corresponds to absolute disagreement with the statement, and the maximum, "5", full agreement.

The respondents were representatives of different age categories and were distributed as follows: under 30 years old - 32.6\%; 30-45 years old - $34.3 \%$; $45-60$ - 29.8\%; over 60 - 3.3\%. 53.3\% of the respondents were male, and $46.7 \%$ were female. As for positions in the firms, $23.7 \%$ were employees, $29.1 \%$ were low-level managers, $24.7 \%$ were middle managers, and $22.5 \%$ were senior managers. In terms of business areas represented, $6.8 \%$ were in agriculture, $9.6 \%$ in mining, $8.5 \%$ in metallurgy, $6.3 \%$ in chemicals, $12.2 \%$ in machine building, $12 \%$ light industry, $10.8 \%$ in food, $12.4 \%$ in construction, $10.6 \%$ in trade, and $10.8 \%$ in finance. And the regional distribution consisted of Vinnitsa, 3.1\%, Volyn, $2.1 \%$, Dnepropetrovsk, 6.3\%, Zhytomyr, 2.6\%, Transcarpathian 3.1\%, Zaporizhzhya, 6.1\%, Ivano- Frankovskaya, 4.9\%, Kievskaya, 6.6\%, Kirovogradskaya, 2.6\%, Lvovskaya, 6.1\%, Nikolaevskaya, $1.9 \%$, Odessa, $7 \%$, Poltava, $4.5 \%$, Rivne, 3.8\%, Sumskaya, 4\%, Ternopil, 3.3\%, Kharkiv, 11.7\%, Kherson, 2.8\%, Khmelnitskaya, 2.3\%, Cherkasskaya, 3.3\%, Chernivtsi, 2.1\%, Chernihiv, $2.3 \%$, and Kiev, $7.5 \%$.

The above representation of respondents in different categories, industries and regions, and their number, testifies to the representativeness of the sample population.

The integral indicator formula (Menke, 2018) was used to comprehensively assess the effectiveness and efficiency of human capital (IHC), taking into account the various aspects of its manifestation in the context of the digitalization of the economy:

$$
I H C=\sum_{i=1}^{n} F_{i} \times d_{i},
$$

where $F_{i}$ - value of the i-th factor of human capital efficiency; $d_{i}$ - the value of the variance of the i-th factor (in shares);

$$
n \text { - number of significant factors }
$$

To determine the factors of human capital efficiency that have a stimulating or disincentive effect on business digitalization, the values of these factors ( $\mathrm{Fi}$ ) and their variance (di) the principal component method in the Statistica 12.0 program was used. The number of observations corresponds to the number of respondents' answers (426), and the number of variables corresponds to the number of questions in blocks 2 and 3 of the questionnaire (30). The variable symbols were presented in the questionnaire. The number of observations exceeds the number of variables by 14.2 times, which indicates the sufficiency of the sample (Menke, 2018). The composition of factors for the human capital efficiency for implementing digital technologies in business has been determined based on factor loads between indicators and factors; Factor loads $\geq|0.7|$ are 'good' (Menke, 2018). The Kaiser criterion determines the number of factors. According to the criterion, factors are selected for which the eigenvalues $\geq 1.0$ (Menke, 2018).

The Fibonacci rule was used to determine the level of human capital efficiency (Adam, Assimakis \& Farina, 2015):

$$
\left\{\begin{array}{l}
I N D_{1}=I N D_{\min }+0.38 \times\left(I N D_{\max }-I N D_{\min }\right) \\
I N D_{2}=I N D_{\min }+0.62 \times\left(I N D_{\max }-I N D_{\min }\right)
\end{array}\right.
$$

where $I N D_{\min }, I N D_{\max }$ - the minimum and maximum possible value of the indicator (factor) of the effectiveness of human capital;

$\left[I N D_{\min } ; I N D_{1}\right]$ - low level of indicator (factor), (IND1; IND2] - medium, (IND2; INDmax] - high level of human capital efficiency.

\section{RESULTS}

In addition to the sample's representativeness, the parameter of the representativeness of the questionnaire is also the reliability of the questionnaire, which in this study was tested using Cronbach's alpha coefficient (Table 1 ). 
Table 1: Indicators of the reliability of the questionnaire to assess the effectiveness of human capital in the context of business digitalization in Ukraine

\begin{tabular}{|c|c|c|c|c|c|}
\hline Index & $\begin{array}{c}\text { Cronbach's alpha } \\
\text { value }\end{array}$ & Index & $\begin{array}{c}\text { Cronbach's alpha } \\
\text { value }\end{array}$ & Index & $\begin{array}{c}\text { Cronbach's alpha } \\
\text { value }\end{array}$ \\
\hline IND1 & 0.89 & $I N D 12$ & 0.88 & $I N D 23$ & 0.86 \\
\hline$I N D 2$ & 0.87 & $I N D 13$ & 0.88 & $I N D 24$ & 0.87 \\
\hline$I N D 3$ & 0.90 & $I N D 14$ & 0.86 & $I N D 25$ & 0.87 \\
\hline$I N D 4$ & 0.88 & $I N D 15$ & 0.88 & $I N D 26$ & 0.88 \\
\hline$I N D 5$ & 0.88 & $I N D 16$ & 0.89 & $I N D 27$ & 0.89 \\
\hline IND6 & 0.89 & $I N D 17$ & 0.88 & $I N D 28$ & 0.87 \\
\hline$I N D 7$ & 0.89 & $I N D 18$ & 0.87 & $I N D 29$ & 0.88 \\
\hline$I N D 8$ & 0.88 & $I N D 19$ & 0.88 & $I N D 30$ & 0.91 \\
\hline$I N D 9$ & 0.87 & $I N D 20$ & 0.88 & Total & 0.88 \\
\hline$I N D 10$ & 0.88 & $I N D 21$ & 0.89 & & \\
\hline$I N D 11$ & 0.88 & $I N D 22$ & 0.87 & & \\
\hline
\end{tabular}

The value of the Cronbach alpha coefficient for the questionnaire was 0.88 , which indicates the questionnaire's reliability since it is within the recommended range of $0.7-$ 0.9 (Hair et al., 2017).
The optimal number of factors was determined by the Kaiser criterion and amounted to 6 , the eigenvalues of which exceed 1.0 (Table 2).

Table 2: Significant factor loadings ( $\geq|0.7|)$ indicators of the effectiveness of human capital in the context of digitalization of business in Ukraine

\begin{tabular}{|c|c|c|c|c|c|c|}
\hline \multirow[b]{2}{*}{ Index } & \multicolumn{6}{|c|}{ Human capital efficiency factors } \\
\hline & $\begin{array}{c}\text { Business } \\
\text { digitalization } \\
\text { perception } \\
\text { factor } \\
\text { Fef }(23.6 \%)^{*}\end{array}$ & \begin{tabular}{|c|} 
Self- \\
development \\
and \\
leadership \\
factor \\
Fdev $(19.4 \%)$
\end{tabular} & $\begin{array}{l}\text { Factor in the } \\
\text { development } \\
\text { of digital } \\
\text { competencies } \\
\text { Fcom }(18.8 \%)\end{array}$ & $\begin{array}{c}\text { The factor of } \\
\text { adaptability } \\
\text { and mobility } \\
\text { Fad (13.1\%) }\end{array}$ & $\begin{array}{c}\text { Factor in } \\
\text { the } \\
\text { developmen } \\
\text { t of digital } \\
\text { culture } \\
\text { Fcul }(12.8 \%)\end{array}$ & $\begin{array}{c}\text { Factor of } \\
\text { creative and } \\
\text { intellectual } \\
\text { potential } \\
\text { Fcreat }(5.8 \%)\end{array}$ \\
\hline IND1 & - & - & - & - & 0.84 & - \\
\hline IND2 & - & - & - & - & 0.91 & - \\
\hline IND3 & - & - & - & - & 0.86 & - \\
\hline IND4 & 0.75 & - & - & - & - & - \\
\hline IND5 & 0.81 & - & - & - & - & - \\
\hline IND6 & 0.86 & - & - & - & - & - \\
\hline IND7 & 0.77 & - & - & - & - & - \\
\hline$I N D 8$ & 0.93 & - & - & - & - & - \\
\hline IND9 & 0.85 & - & - & - & - & - \\
\hline IND10 & - & 0.90 & - & - & - & - \\
\hline IND11 & - & 0.88 & - & - & - & - \\
\hline IND12 & - & 0.93 & - & - & - & - \\
\hline IND13 & - & - & - & - & - & 0.79 \\
\hline IND14 & - & - & - & 0.81 & - & - \\
\hline IND15 & - & 0.86 & - & - & - & - \\
\hline IND16 & - & 0.91 & - & - & - & - \\
\hline
\end{tabular}


Table 2: Continued

\begin{tabular}{|l|c|c|c|c|c|c|}
\hline IND17 & - & - & - & -0.84 & - & - \\
\hline IND18 & - & - & - & 0.91 & - & - \\
\hline IND19 & - & - & - & 0.83 & - & - \\
\hline IND20 & - & - & - & - & - & 0.84 \\
\hline IND21 & - & - & - & -0.76 & - & - \\
\hline IND22 & - & - & - & - & - & 0.91 \\
\hline IND23 & - & 0.79 & - & - & - & - \\
\hline IND24 & - & - & 0.89 & - & - & - \\
\hline IND25 & - & - & - & -0.86 & - & - \\
\hline IND26 & - & - & 0.84 & - & - & - \\
\hline IND27 & - & - & 0.91 & - & - & - \\
\hline IND28 & - & - & 0.77 & - & - & - \\
\hline IND29 & - & - & 0.90 & - & - & - \\
\hline IND30 & - & - & 0.85 & - & - & - \\
\hline
\end{tabular}

The most significant factor in determining the effectiveness of human capital and its impact on digitalization development is the factor of its perception. This factor characterizes the effectiveness of digitalization in the opinion of company personnel. It reflects the attitude of personnel to the advantages and disadvantages of using digital technologies: increasing labor productivity, intellectual development of personnel, maximizing enterprise profits, reducing the level of corruption, and soundness and objectivity of decision-making, on the one hand, and a decrease in employment, legal lack of regulation, and the high cost of technology on the other hand. According to the calculations, the factor's contribution to the development of business digitalization was $23.6 \%$.

The factor of self-development and leadership determines the potential for the development of digitalization through the formation of metacompetencies of personnel, e.g. to constantly learn and improve themselves to acquire competencies and develop psychological characteristics necessary for using digital technologies, as well as the ability to show leadership abilities in a changing business environment. The variance of the factor was $19.4 \%$.

The variance of the digital competence factor was $18.8 \%$. This factor determines the objective basis for the digitalization of business - the availability of competencies among personnel, without which the development of digital technologies and their effective use are impossible. This is the ability to work with large amounts of data, use digital technologies to exchange information, the ability to protect digital content from cyber threats, the distortion of real information and other threats, the ability to use your digital skills, and the willingness to share experiences with colleagues.

The factor of adaptability and mobility by $13.1 \%$ determines the development of digital technologies in business due to the corresponding level of human capital effectiveness. It characterizes the individual psychological characteristics of a person associated with the ease of adaptation to new conditions.

The factor of the development of digital culture, $12.8 \%$, determines the development of business digitalization and describes human capital as understanding the need for digitalization of business on which the prospects for digitalization depend.

The factor of creative and intellectual potential characterizes the development of creativity and intelligence, the presence of which will allows the mastering of new competencies and using them effectively. The influence of the factor on the possibilities of developing business digitalization, expressed as a percentage of variance, was $5.8 \%$.

These factors determine the development of business digitalization and the efficiency of using digital technologies since they characterize the level of digital competencies of 
company staff, the ability to use and develop them by adapting to changing business conditions through adaptability and mobility, the ability to self-develop, leadership skills, and creative and intellectual potential. They also characterize the desire to develop the necessary competencies and adapt to changing business conditions through awareness of the opportunities and threats for business, and personally, from the use of digital technologies, which is reflected through the factor of perception of business digitalization and the factor of development of digital culture.
The completeness of factorization, and the adequacy of the conducted factor analysis, is evidenced by the cumulative percentage of the selected factors' variance (93.5\%), which exceeds the sufficient level of $80 \%$ (Menke, 2018).

The values of indicators IND1 through IND9 are measured in the interval [0; 10], and for indicators IND10 through IND30 [0; five]. In this regard, using formula (2), the ranges of levels of indicators and factors of the effectiveness of human capital are formed (see Table 3 ).

Table 3: Ranges of levels of indicators and factors of the human capital effectiveness in the context of digitalization of business in Ukraine

\begin{tabular}{|c|c|c|c|}
\hline \multirow{2}{*}{ Indicator / Factor } & \multicolumn{3}{|c|}{ Levels } \\
\cline { 2 - 4 } & Low & Medium & High \\
\hline IND1-IND9 & {$[0 ; 3.8]$} & $(3.8 ; 6.2]$ & $(3.2 ; 10]$ \\
\hline IND10-IND30 & {$[0 ; 1.9]$} & $(1.9 ; 3.1]$ & $(3.1 ; 5]$ \\
\hline Fef & {$[0 ; 1.9]$} & $(2.0 ; 3.1]$ & $(3.3 ; 5.3]$ \\
\hline FdeV & {$[0 ; 2.0]$} & $(2.0 ; 3.2]$ & $(3.2 ; 5.2]$ \\
\hline Fcom & {$[0 ; 2.0]$} & $(-0.6 ; 0.6]$ & $(0.6 ; 2.6]$ \\
\hline Fad & {$[-2.5 ;-0.6]$} & $(1.0 ; 1.6]$ & $(1.6 ; 2.6]$ \\
\hline Fcul & {$[0 ; 1.0]$} & $(1.0 ; 1.6]$ & $(1.6 ; 2.5]$ \\
\hline FCreat & {$[0 ; 1.0]$} & $(1.3 ; 2.3]$ & $(2.3 ; 4.0]$ \\
\hline IHC & {$[-0.3 ; 1.3]$} & & \\
\hline
\end{tabular}

For the studied business categories, no statistically significant differences (according to Student's criterion) were found in the respondents' assessments, which indicates the universality of the results obtained to Ukrainian companies. In this regard, it seems possible to bring the average values for the study sample of the values of human capital development indicators and their levels (Table 4). The average values of the factors were calculated using the Statistica 12.0 program.

Of the set of indicators, only IND17, IND21 and IND25 hinder the development of digitalization: their higher values negatively affect personnel's ability to adapt to innovations. These indicators have negative factor loadings with the factor of adaptability and mobility. Other indicators, the growth of which indicates an increase in human capital efficiency from the standpoint of opportunities for the development of business digitalization, have positive factor loads with corresponding factors. This indicates that all the factors identified are stimulators in the development of business digitalization - their higher value indicates the intensification of digitalization development.

The results indicate that a low level of digitalization perception exerts the main destructive influence on the development of business digitalization from its effectiveness for business, the development of digital competencies, and digital development culture. The factors of self-development and leadership, adaptability and mobility, and creative and intellectual potential are average. The consequence of these factors' influence is the low level of the integral indicator of the effectiveness of human capital in the context of business digitalization in Ukraine (IHC $=1.2$ ). 
Table 4: Average values of indicators and factors of the human capital effectiveness in the context of business digitalization in Ukraine

\begin{tabular}{|c|c|c|c|c|c|c|c|c|}
\hline $\begin{array}{c}\text { Indicat } \\
\text { or / } \\
\text { Factor }\end{array}$ & $\begin{array}{c}\text { Average } \\
\text { value }\end{array}$ & Level & $\begin{array}{c}\text { Indicat } \\
\text { or / } \\
\text { Factor }\end{array}$ & $\begin{array}{c}\text { Average } \\
\text { value }\end{array}$ & Level & $\begin{array}{c}\text { Indicator } \\
\text { / Factor }\end{array}$ & $\begin{array}{c}\text { Average } \\
\text { value }\end{array}$ & Level \\
\hline IND1 & 2.9 & Low & IND14 & 2.4 & Medium & IND27 & 2.6 & Medium \\
\hline IND2 & 1.5 & Low & IND15 & 2.2 & Medium & IND28 & 1.9 & Low \\
\hline IND3 & 1.1 & Low & IND16 & 2.2 & Medium & IND29 & 0.1 & Low \\
\hline IND4 & 2.7 & Low & IND17 & 2.3 & Medium & IND30 & 1.9 & Low \\
\hline IND5 & 4.0 & Medium & IND18 & 2.4 & Medium & Fef & 1.5 & Low \\
\hline IND6 & 4.8 & Medium & IND19 & 2.9 & Medium & Fdev & 2.3 & Medium \\
\hline IND7 & 2.3 & Low & IND20 & 2.7 & Medium & Fcom & 1.5 & Low \\
\hline IND8 & 3.3 & Low & IND21 & 2.4 & Medium & Fad & 0.2 & Medium \\
\hline IND9 & 0.4 & Low & IND22 & 1.8 & Low & Fcul & 0.5 & Low \\
\hline IND10 & 2.3 & Medium & IND23 & 2.0 & Medium & Fcreat & 1.2 & Medium \\
\hline IND11 & 1.8 & Low & IND24 & 0.3 & Low & IHC & 1.2 & Low \\
\hline IND12 & 2.7 & Medium & IND25 & 2.2 & Medium & & & \\
\hline IND13 & 2.5 & Medium & IND26 & 2.1 & Medium & & & \\
\hline
\end{tabular}

The low level of development of digital competencies is because the personnel of companies (IT companies were not included in the study sample) do not have a special IT education, which makes it possible to protect a business from possible threats that arise when using digital technologies (the average value of the IND29 indicator in the sample was 0.1 points out of 5 maximum) and do not have programming skills (the value of the IND24 indicator is 0.3 points). This is reflected in the values of other indicators of this factor, which are in the range of 1.9-2.6. But the low values of this factor are partially offset by the average level of development of factors of adaptability and mobility, self-development and leadership, and creative and intellectual potential, which indicates the readiness of staff to learn, improve themselves and master new competencies, which is facilitated by the intellectual development of personnel.

The potential for the development of digitalization due to human capital development is calculated as an increase in the integral indicator when the maximum possible values of the factors for the development of human capital are reached.

Considering the actual values of the factors and their variances, the highest potential for the development of digitalization at the expense of human capital is the factor of perception of business digitalization. Achieving the potential value can increase the integral indicator, which characterizes the possibilities for developing digital technologies due to the appropriate level of development and efficiency of human capital by $67.3 \%$. Achievement of the potential value of self-development and leadership by $46.3 \%$, the development of digital competencies by $55.6 \%$; adaptability and mobility by $25.2 \%$, development of digital culture by $22.2 \%$, and creative and intellectual potential by $6.4 \%$.

\section{DISCUSSION}

This study used empirical modeling to determine the qualitative characteristics of the effectiveness of human capital at the current stage of development of business digitalization in Ukraine. The proposed approach, in contrast to those available in the scientific literature on the consideration of the problems of human capital compliance to the level of the digitalization of the economy (Voronin et al., 2020; Hu, 2021), was based on assessing the efficiency of human resources, not productivity (Jeske, Würfels \& Lennings, 2021). This allows us to consider the priority of the human factor in the formation of the digital market space and not the scientific and technical factors. Since it is the technical capabilities of the means of 
production that limit the further growth of labor productivity, it becomes obvious that it is the scientific and technical factor that acts as the main driving force for increasing labor productivity and without its further development and improvement, it seems impossible to increase labor productivity. Whereas in the context of informatization, it is the human factor that becomes the driving force of digital transformation and goes beyond technology alone, reflects a direction of thinking that encompasses continuous innovation, decision making on an equal footing, and the integration of technology into all aspects of the business.

Also, the obtained empirical assessments of the efficiency of human capital allow the most reliable assessment of the existing problems of digital transformation in Ukraine, taking into account the existing level of development of the economy, its digitalization, and the level of compliance and inconsistency of human capital. This, in turn, can make it possible to determine the main strategic directions for increasing the quality parameters of human capital in the country and accelerate digital transformation.

According to the study results, the main threat to the development of digitalization in Ukraine is the immaturity of digital culture and the perception of business digitalization. The companies' personnel do not consider digitalization possible through the development of the company (indicators IND5-IND9) and personal development (indicator IND4). According to most respondents, digitalization is a reduction in jobs and unemployment (for $48.1 \%$ of respondents), while the opportunity to receive higher wages through the use of intellectual and creative abilities is $3.1 \%$ of respondents.

For business, most respondents, 50.5\%, see digitalization as an opportunity to improve the efficiency of individual departments (processes, operations), which will not significantly affect the company's efficiency. Digitalization is an opportunity to attract additional investment, ensure competitiveness, and maximize its profits for only $14.8 \%$ of respondents. For $5.9 \%$, this positive effect is already possible, and for $75.1 \%$ in $5-10$ years, taking into account the existing conditions of economic development, the level of informatization, infrastructure development, and for $9.2 \%$ it is ineffective for business under any conditions.

Skepticism regarding the prospects for the development of digital technologies is also caused by the disagreement with the fact that digitalization will reduce the level of corruption, increase objectivity in decision-making (IND8 = 3.3); the existence of the risk of information leakage, creating a fake reality, and making wrong decisions using digital technologies $($ IND9 $=0.4)$.

In many ways, the low level of development of the perception of business digitalization is due to the low level of digital culture development. The majority of respondents, 95.1\%, view digitalization from the technical and technological perspective (as an opportunity to automate production), while not realizing that digitalization can also optimize management processes. The priority criterion for choosing contractors for $71.9 \%$ of respondents is the low cost of services provided and a low level of risk, while the possibility of creating more "reasonable" products (services), 2.6\% of respondents.

But in addition to the lack of understanding by staff of the essence of digitalization, there are also objective obstacles to the development of digitalization - the legal lack of regulation. In Ukraine, the Concept for the Development of the Digital Economy and Society (Cabinet of Ministers of Ukraine, 2018) and an action plan for its implementation have been adopted. Simultaneously, the issues of distributing responsibility for decisions made using artificial intelligence technologies are ensuring property rights when creating products (services) using these technologies and personal data protection.

The results obtained on the system of human capital efficiency factors in the context of digital transformation do not apply to other countries and regions since it requires the recalculation of the values of factors and their significance in the integral model, taking into account the level of development of the country's economy and the level of its digitalization, living standards, literacy, education, longevity human potential of the study area, etc. 


\section{CONCLUSION}

Based on the results obtained within the framework of this study, the following conclusions can be made. In modern conditions, the beginning of business digitalization in Ukraine - human capital efficiency - is at a low level, which does not contribute to the intensive, innovative development of the country's economy and is one of the destructive factors of digitalization. The highest priority area for increasing the efficiency of human capital to intensify the digitalization of business in Ukraine today is developing the factor of perception of business digitalization. An increase in the efficiency of human capital is seen by increasing the awareness of personnel about the essence of digitalization, the current state and promising directions of its implementation, the state of legal regulation, the possible impact of digitalization on profitability, investment attractiveness, the competitiveness of the company, labor productivity, the degree of validity and objectivity of decision-making at the enterprise, and opportunities for staff development and the like.

\section{REFERENCES}

Adam, M., Assimakis, N., \& Farina, A. (2015). Golden section, Fibonacci sequence and the time invariant Kalman and Lainiotis filters. Applied Mathematics and Computation, 250, 817-831. https://doi.org/10.1016/j.amc.2014.11.022

Ballestar, M.T., Díaz-Chao, Á., Sainz, J., \& TorrentSellens, J. (2020). Knowledge, robots and productivity in SMEs: Explaining the second digital wave. Journal of Business Research, 108, 119-131. https://doi.org/10.1016/j.jbusres.2019.11.01 7

Cabinet of Ministers of Ukraine. (2018). Concept of digital economy and society development and action plan for its implementation for years 2018 - 2020 https://zakon.rada.gov.ua/laws/show/672018-\%D1\%80?lang=en\#Text

Chen, Y. (2020). Improving market performance in the digital economy. China Economic Review, 62, 101482. https://doi.org/10.1016/j.chieco.2020.10148 2

Congressional Research Service. (2021). Global Economic Effects of COVID-19. https://fas.org/sgp/crs/row/R46270.pdf

European Commission. (2019). The Digital Competence Framework 2.0.

https://ec.europa.eu/jrc/en/digcomp/digitalcompetence-framework

Faggian, A., Partridge, M., \& Malecki, E. (2016). Creating an environment for economic growth: creativity, entrepreneurship or human capital? MPRA, 71445.

Hair, J. F., Hult, G. M., Ringle, C. M., \& Sarstedt, M. (2017). A primer on partial least squares structural equation modeling (PLS-SEM). Thousand Oaks, CA: Sage Publications.

Horoshko, O.-I., Horoshko, A., Bilyuga, S., \& Horoshko, V. (2021). Theoretical and Methodological Bases of the Study of the Impact of Digital Economy on World Policy in 21 Century. Technological Forecasting and Social Change, 166, 120640. https://doi.org/10.1016/j.techfore.2021.120 640

Hu, G.-G. (2021). Is knowledge spillover from human capital investment a catalyst for technological innovation? The curious case of fourth industrial revolution in BRICS economies. Technological Forecasting and Social Change, 162, 120327. https://doi.org/10.1016/j.techfore.2020.1203 27

International Labour Organization. (2021). Statistics on labour productivity. Retrieved April 1, 2021, from https://ilostat.ilo.org/topics/labourproductivity/

Jeske, T., Würfels, M., \& Lennings, F. (2021). Development of Digitalization in Production Industry - Impact on Productivity, Management and Human Work. Procedia Computer Science, 180, 371-380. https://doi.org/10.1016/j.procs.2021.01.358

Law, S.H., Naseem, N.A.M., Lau, W.T., \& Trinugroho, I. (2020). Can innovation improve income inequality? Evidence from panel data. Economic Systems, 44, 4, 100815. 
https://doi.org/10.1016/j.ecosys.2020.10081 5

Mahmood, T., \& Mubarik, M.S. (2020). Balancing innovation and exploitation in the fourth industrial revolution: Role of intellectual capital and technology absorptive capacity. Technological Forecasting and Social Change, 160, 120248.

https://doi.org/10.1016/j.techfore.2020.1202 48

Megits, N., Neskorodieva, I., \& Schuster, J. (2020). Impact assessment of the COVID19 on trade between Eastern Europe and China. Journal of Eastern European and Central Asian Research (JEECAR), 73), 385-399. https://doi.org/10.15549/jeecar.v7i3.579

Menke, W. (2018). Factor Analysis. Geophysical Data Analysis (Fourth Edition). New York: Academic Press, 207-222.

Portulans Institute. (2021). NRI 2020 Countries. Retrieved April 1, 2021, from https://networkreadinessindex.org/nri2020-countries/\#complete-ranking

Ragnedda, M. (2018). Conceptualizing digital capital. Telematics and Informatics, 35, 8, 2366-2375. https://doi.org/10.1016/j.tele.2018.10.006.

State Statistics Service of Ukraine. (2021). Retrieved April 1, 2021, from http://www.ukrstat.gov.ua/

Tewathia, N., Kamath, A., \& Ilavarasan, P.V. (2020). Social inequalities, fundamental inequities, and recurring of the digital divide: Insights from India. Technology in Society, 61, 101251. https://doi.org/10.1016/j.techsoc.2020.1012 51

The Fletcher School. (2021). Digital Intelligence Index. Retrieved April 1, 2021, from https://digitalintelligence.fletcher.tufts.edu/ trajectory

The human capital effectiveness in the context of the digital transformation of the economy (2021).

https://docs.google.com/forms/d/1tiRkunx3 13TxK5rl6ojftQdov6C_8trnFpvLWTuVUU/edit

Voronin, B.A., Chupina, I.P., Voronina, Ya.V., Chupin, Yu.N., Zarubina, E.V., \& Simachkova,
N.N. (2020). The role of human capital in the digitalization of the country's agriculture. E3S Web of Conferences, 176, 05016. https://doi.org/10.1051/e3sconf /202017605016

Walwei, U. (2016). Digitalization and structural labour market problems: The case of Germany. ILO Research Paper No. 17.

Yanovska, V., Levchenko, O., Tvoronovych, V., \& Bozhok, A. (2019). Digital Transformation of the Ukrainian Economy: Digitization and Transformation of Business Models. SHS Web of Conferences, 67. https://doi.org/10.1051/shsconf /20196705003

Yasmin, T., El Refae, G. A., \& Eletter, S. (2019). Sectoral productivity in Hungarian economy: an input-output linkages approach. Journal of Eastern European and Central Asian Research (JEECAR), 6(2), 344355. https://doi.org/10.15549/jeecar.v6i2.318

\section{ABOUT THE AUTHORS}

Volodymyr Rodchenko, email: rodchenko@karazin.ua

Volodymyr Rodchenko, DSc (Econ), V. N. Karazin Kharkiv National University, Ukraine.

Ganna Rekun, PhD (Econ), V. N. Karazin Kharkiv National University, Ukraine.

Larysa Fedoryshyna, DSc (Econ), Associate Professor, University of Economics and Entrepreneurship, Khmelnytsk, Ukraine.

Ihor Roshchin, Ed.D., Professor, University of Customs and Finance, Dnipro, Ukraine.

Svitlana Gazarian, D.P.A. Professor, Kharkiv regional institute of public administration of the National Academy of Public Administration under the President of Ukraine. 